Seed Science Research

cambridge.org/ssr

\section{Research Paper}

Cite this article: Isobe $\mathrm{K}$, Sugiyama $\mathrm{H}$, Tamamushi K, Shimizu T, Kobashi K, Higo M (2018). Effects of day length on pollen tube elongation, embryo formation and seed development after flowering in quinoa (Chenopodium quinoa Willd.). Seed Science Research 28, 272-276. https://doi.org/10.1017/ S0960258518000223

Received: 4 February 2018

Accepted: 30 April 2018

First published online: 18 June 2018

Keywords:

day length; embryo formation; quinoa; seed development

\section{Author for correspondence:}

Katsunori Isobe

Email:isobe64@brs.nihon-u.ac.jp

\section{Effects of day length on pollen tube elongation, embryo formation and seed development after flowering in quinoa (Chenopodium quinoa Willd.)}

\author{
Katsunori Isobe, Hikaru Sugiyama, Katsura Tamamushi, Taito Shimizu, \\ Kana Kobashi and Masao Higo
}

College of Bioresource Sciences, Nihon University, 1866 Kameino, Fujisawa-city, Kanagawa, 252-0880, Japan.

\begin{abstract}
The objective of this study was to evaluate the effect of day length after flowering on pollen tube elongation, embryo formation and seed development. The quinoa varieties used in this study were Amarilla de Marangani (valley type) and NL-6 (sea-level type). After sowing, the quinoa plants were cultivated in growth cabinets. From sowing to flowering, plants were exposed to a $15 \mathrm{~h}$ day length regime. After flowering, the plants were grown under either a $15 \mathrm{~h}$ or $11 \mathrm{~h}$ day length regime. The elongation of the pollen tube and the formation of the early embryo were not inhibited in either Amarilla de Marangani or NL-6 under the 11 or $15 \mathrm{~h}$ day length regimes. Although growth of the embryo in NL-6 was not inhibited by the $15 \mathrm{~h}$ day length regime after flowering, the same was not observed in the case for Amarilla de Marangani. In Amarilla de Marangani, seed diameter at 8 and 14 days after flowering under the $11 \mathrm{~h}$ day length regime was larger than that of seeds grown under the $15 \mathrm{~h}$ day length regime. Thus, the decrease in the number of seeds in Amarilla de Marangani grown under the $15 \mathrm{~h}$ day length regime may be caused by the suspension of embryo growth after fertilization.
\end{abstract}

\section{Introduction}

Quinoa (Chenopodium quinoa Willd.) is a crop that was domesticated in South America 1000 years ago (Repo-Carrasco et al., 2003; Costa Tártara et al., 2012). This species is classified into ecotypes (including the altiplano, sea-level and valley types) based on their place of origin (Galwey, 1989; Wilson, 1990; Fuentes et al., 2009). The sea-level type quinoa originated in Southern Chile, and the valley type quinoa originated in the high altitude terrains (2000$3000 \mathrm{~m}$ above sea level) of Bolivia (Risi and Galwey, 1984, 1989). Several studies have reported differences in the effect of day length on seed formation and seed growth among ecotypes after flowering (Risi and Galwey, 1991; Bertero et al., 1999; Ujiie et al., 2007; Cheristiansen et al., 2010; Hirich et al., 2014).

Several studies have reported that day length after flowering may affect seed-set, embryo development and seed development in numerous annual crops (Thomas and Raper, 1976; Cure et al., 1982; Summerfield et al., 1991; Linnemann, 1993; Lobell et al., 2000; Lagercrantz, 2009). For example, in soybean the seed dry weight and seed number increased under a $15 \mathrm{~h}$ day length regime (Cure et al., 1982). The critical photoperiod requirement for seed-filling in the early-maturing cultivars was reported to be longer than that in the latematuring cultivars (Thomas and Raper, 1976). The seed-set percentage in sunflowers grown under a $24 \mathrm{~h}$ day length regime was very low compared with that of plants grown under a $16 \mathrm{~h}$ day length period (Lobell et al., 2000). In bambara groundnut, embryo growth ceased when plants were grown under an $11.5 \mathrm{~h}$ day length regime but was allowed to continue when plants were grown under a $14.0 \mathrm{~h}$ day length regime after flowering (Linnemann, 1993).

The seed developmental stages in quinoa are as follows: (1) pollen germination and pollen tube elongation from stigma to ovule; (2) fertilization and embryo formation; and (3) embryo and seed growth. In quinoa, seed growth of sea-level type quinoa was not suppressed under either an 11 or $14 \mathrm{~h}$ day length regime after flowering. In contrast, seed growth of the valley type quinoa was suppressed under a $14 \mathrm{~h}$ day length regime, but not under an $11 \mathrm{~h}$ day length regime after flowering (Ujiie et al., 2007; Isobe et al., 2016). However, the reason behind inhibition of seed development under long days after flowering in the valley type quinoa remains unclear. Because the nutritional characteristics of quinoa seeds were reassessed, an increase in the amount of quinoa consumption is foreseen (Armeja et al., 2015). There is good potential for increased production of quinoa in the world. At present, quinoa is not cultivated in Japan. However, we believe that the cultivation of quinoa in Japan may become more important in the future. The objective of this study was to evaluate the effects of day length after flowering on pollen tube elongation, embryo formation and seed growth in two quinoa varieties. 


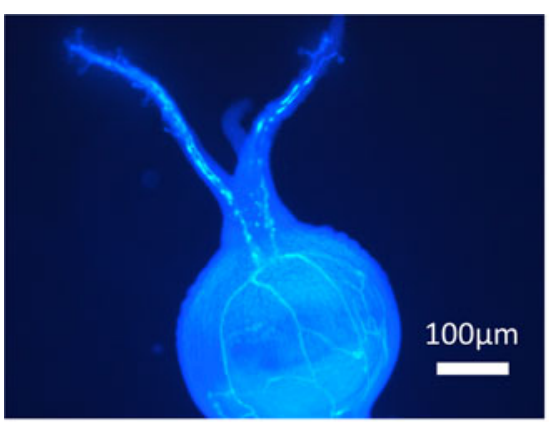

Elongation

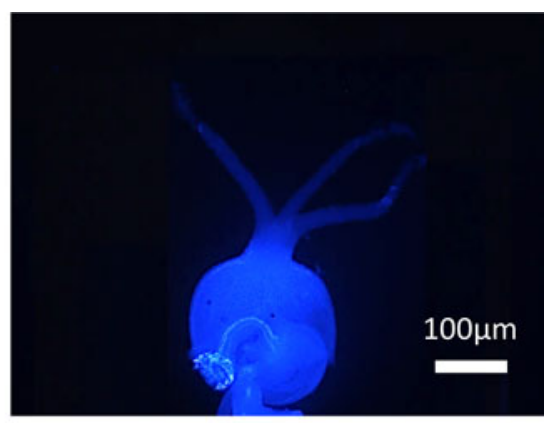

Non-elongation
Figure 1. The elongation or non-elongation of pollen tube from stigma to ovule.

\section{Materials and methods}

\section{Cultivation conditions and plots}

The quinoa varieties tested in this study were Amarilla de Marangani (valley type) and NL-6 (sea-level type). Ten seeds were sown in 1/ $5000 \mathrm{a}$ pots containing $3 \mathrm{~kg}$ field soil (Andosol), and $4.57 \mathrm{~g}$ compound fertilizer $\left(\mathrm{N}-\mathrm{P}_{2} \mathrm{O}_{5}-\mathrm{K}_{2} \mathrm{O}=14-14-14\right)$. The seedlings were thinned to two plants per pot at the expansion stage (plants showing two or three leaves). After sowing, the quinoa plants were placed in growth cabinets (Koito Kogyo; FR-535A-S2). From sowing to maturity, the day temperature was set to $25^{\circ} \mathrm{C}$, and the night temperature to $22^{\circ} \mathrm{C}$. From sowing to flowering, the plants were exposed to a $15 \mathrm{~h}$ day length regime. After flowering, the plants were grown under either a $15 \mathrm{~h}$ ( $15 \mathrm{~h}$ plot) or an $11 \mathrm{~h}$ day ( $11 \mathrm{~h}$ plot) length regime. At flowering, sepals on each flower were marked with different colours to determine the flowering date.

\section{Assessment of pollen tube elongation in the style}

Two days after flowering, 150 flowers (50 flowers $\times 3$ plants) of each plot were collected. After collection, the flowers were fixed in Carnoy's solution (ethanol:chloroform:glacial acetic acid = 6:3:1). Subsequently, the flower samples were soaked in $1 \mathrm{~N}$ $\mathrm{KOH}$ at $60^{\circ} \mathrm{C}$ for $10 \mathrm{~min}$, and stained in a $1 \%$ aniline blue solution for $24 \mathrm{~h}$. The elongation of pollen tubes in the style was observed under a fluorescence microscope (Leica DM-2500). The ratio of elongated pollen tubes to the number of styles (the number of total elongated pollen tubes the number of observed styles) was calculated for each plot and variety of quinoa.

\section{Assessment of embryo growth}

Flowers from each plot were collected at 2, 4, 6, 8 and 14 days after flowering. After collection, the flowers were fixed in FAA solution (50\% ethanol:acetic acid:formalin $=18: 1: 1)$, and then dehydrated by immersion in an alcohol series ranging from $40 \% n$-butanol, $25 \%$ ethanol in water to absolute $n$-butanol. The sections were then embedded in paraffin. Serial transversal sections $(10-20 \mu \mathrm{m}$ thick) were cut and stained using Mayer's Hematoxylin solution for $20 \mathrm{~min}$. The sections were observed under a light microscope (Olympus BX50-F4).

\section{Seed diameter}

At 8 and 14 days after flowering, 30 flowers (50 flowers $\times 3$ plants) from each plot were collected, and seed diameter was measured using a stereoscopic microscope (Olympus SZX12).

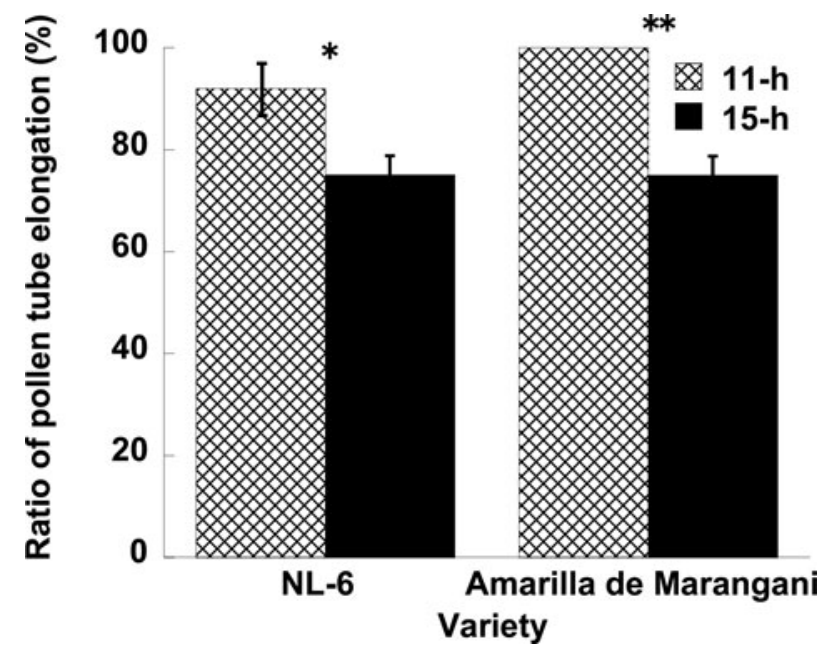

Figure 2. Effects of day length after flowering on the pollen tube elongation. ${ }^{\star \star} 1 \%$ and ${ }^{\star} 5 \%$ level of significance between 11 and $15 \mathrm{~h}$ by $t$-test, respectively. Replications $=3$.

\section{Flower number and seed number at maturity}

At maturity, 10 plants of each plot were harvested and the number of flowers, and the seeds per plant were enumerated. The seed-set ratio (the number of seeds divided by the number of flowers) was calculated. In this experiment, seeds with a diameter $>1.0 \mathrm{~mm}$ were considered viable.

\section{Statistical analysis}

All values are expressed as means. Significant differences between the $11 \mathrm{~h}$ and the $15 \mathrm{~h}$ day length plots for each variety were determined by $t$-test. The data pertaining to pollen tube elongation ratio and seed per flower ratio were statistically analysed after angular transformation. Statistical analysis was performed using Kaleida Graph version 4.1 software; $P<0.05$ was considered significant.

\section{Results}

\section{Assessment of pollen tube elongation in the style}

When a pollen tube was elongated from stigma to the ovule, a fluorescent line was observed in the style (Fig. 1). In NL-6, the ratio of elongated pollen tubes per style was significantly higher under the $11 \mathrm{~h}$ than under the $15 \mathrm{~h}$ day length (Fig. 2). In Amarilla de Marangani, the ratio of elongated pollen tubes per 


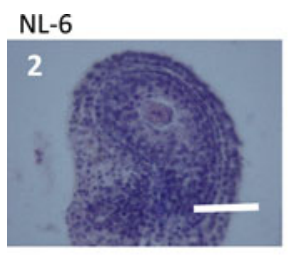

Amarilla de Marangani

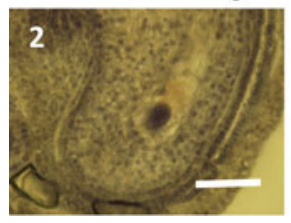
length regime after flowering. 2, 4, 8, 14: days after flowering. White scale bar, $100 \mu \mathrm{m}$; red scale bar, $1000 \mu \mathrm{m}$.
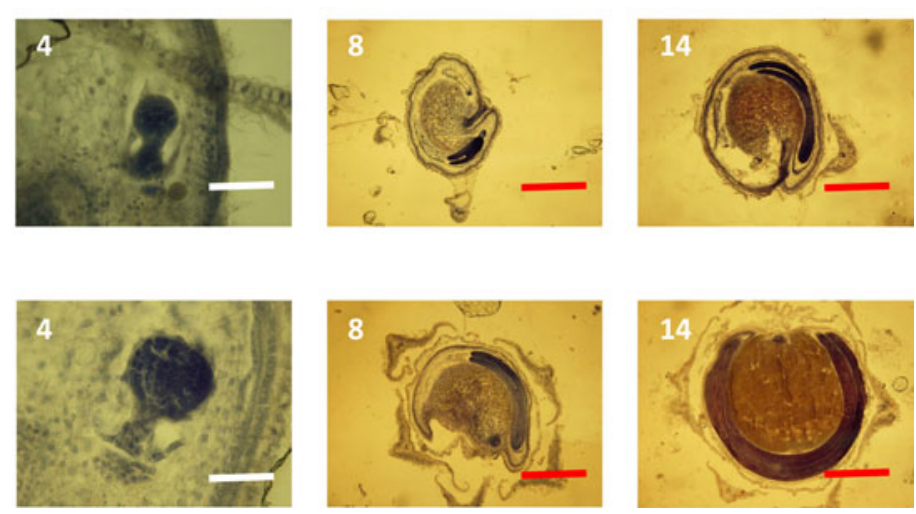

style was significantly higher under the $11 \mathrm{~h}$ compared with $15 \mathrm{~h}$ day length (100 and 75\%, respectively) regime (Fig. 2).

\section{Embryo growth \\ NL-6 and Amarilla de Marangani under an $11 \mathrm{~h}$ day length regime}

At 2 days after flowering, the early embryo was observed in the ovules of both varieties. The globular embryo was observed at 4 days after flowering. At 8 days, the cotyledon and the radicle were observed in the ovules of both varieties. Between 8 and 14 days after flowering, the cotyledon and the radicle elongated, and the endosperm widened in the seeds of both varieties (Fig. 3).

NL-6 and Amarilla de Marangani under a 15 h day length regime At 2 days after flowering, the early embryo was observed in the ovules of both varieties. At 6 days after flowering, the globular embryo was observed in the ovules of NL- 6 but not in the ovules of Amarilla de Marangani. At 8 days after flowering, the heartshaped embryo was observed in the ovule of NL-6 but not in the ovules of Amarilla de Marangani. At 14 days after flowering, the cotyledon and the radicle were observed and the endosperm widened in the seeds of NL-6 (Fig. 4).

\section{Seed diameter}

\section{NL-6}

The seed diameter under the $11 \mathrm{~h}$ and the $15 \mathrm{~h}$ day length regimes was increased from flowering to 14 days after flowering. Therefore, there were no significant differences in the seed diameter at flowering, and at 8 and 14 days after flowering between the $11 \mathrm{~h}$ and the $15 \mathrm{~h}$ day length plot (Figs 5 and 6).

\section{Amarilla de Marangani}

The seed diameter under the $11 \mathrm{~h}$ day length regimes was increased from flowering to 14 days after flowering. The seed diameter under the $15 \mathrm{~h}$ day length regimes was not increased from flowering to 14 days after flowering. There were no significant differences in seed diameter at flowering between the $11 \mathrm{~h}$ and the $15 \mathrm{~h}$ plots. However, there were significant differences in seed diameter at 8 and 14 days after flowering between the $11 \mathrm{~h}$ and $15 \mathrm{~h}$ day length plots (Figs 5 and 6).

\section{Number of flowers and seeds at maturity}

NL-6

There were no significant differences in the numbers of flowers and seeds between the $11 \mathrm{~h}$ and the $15 \mathrm{~h}$ day length regimes. However, the ratio of seeds to flowers was 81.3 and $55.4 \%$ under the $11 \mathrm{~h}$ and the $15 \mathrm{~h}$ day length regimes, respectively, and thus significantly higher under the $11 \mathrm{~h}$ day length regime (Table 1).

\section{Amarilla de Marangani}

The number of flowers per plant was significantly higher under the $15 \mathrm{~h}$ day length regime $(P=0.05)$. The number of seeds per plant was 1891.7 and 0.0 under the $11 \mathrm{~h}$ and the $15 \mathrm{~h}$ day length regimes, respectively, and thus significantly higher under the $11 \mathrm{~h}$ day length. The seed to flower ratio was significantly higher under the $11 \mathrm{~h}$ day length regime (Table 1 ).

\section{Discussion}

Quinoa (Chenopodium quinoa Willd.) is classified into certain ecotypes (including the altiplano, sea-level and valley types) based on their place of origin (Galwey, 1989; Wilson, 1990; Fuentes et al., 2009). In the valley types, a shorter day length after flowering is required for seed-set and seed growth (Ujiie et al., 2007; Isobe et al., 2012, 2016). This characteristic of the valley type quinoa was one of the most important limitations for the expansion of its cultivated area. In Japan, the longest day length in Tokyo (latitude $35.7^{\circ} \mathrm{N}$ ) in summer, is approximately $14 \mathrm{~h} 30 \mathrm{~min}$, but in Sapporo (latitude $43.1^{\circ} \mathrm{N}$ ), it is over $15 \mathrm{~h}$. In this study, the elongation of pollen tube and the formation of early embryo in Amarilla de Marangani and NL-6 were not inhibited under the $11 \mathrm{~h}$ and the $15 \mathrm{~h}$ day length regimes (Figs 2-4). Moreover, embryo growth of NL-6 was not inhibited under the $15 \mathrm{~h}$ day length regime, which was not the case for Amarilla de Marangani (Fig. 4). In addition, in Amarilla de Marangani, the seed diameter at 8 and 14 days after flowering under the $11 \mathrm{~h}$ day length regime was larger than that of seeds obtained under the $15 \mathrm{~h}$ day length regime (Figs 5 and 6). This result is in agreement with previous reports (Ujiie et al., 2007; Isobe et al., 2012, 2016). Thus, the cultivation of Amarilla de Marangani is difficult in northern areas of Japan, for example Sapporo. The decrease in seed number under the $15 \mathrm{~h}$ day length regime (Table 1 ) may be caused by the suspension of embryo growth after fertilization. However, we used only one sea-level type variety (NL-6) and one valley type variety (Amarilla de Marangani) in this 


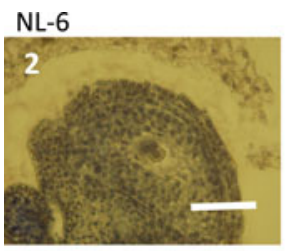

Amarilla de Marangani
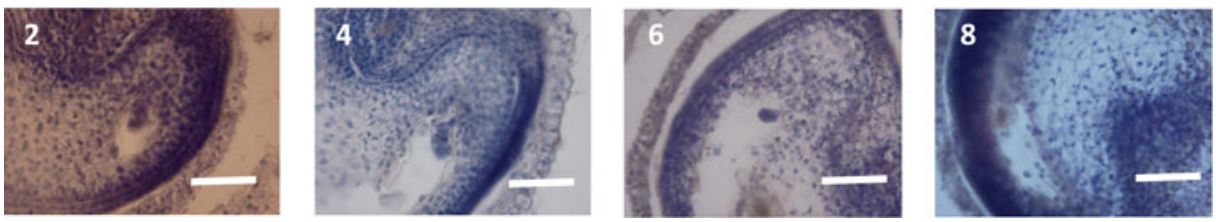

Figure 4. Embryo development under $15 \mathrm{~h}$ day length regime after flowering. 2, 4, 6, 8, 14: days after flowering. White scale bar, $100 \mu \mathrm{m}$; blue scale bar, $400 \mu \mathrm{m}$; red scale bar, $1000 \mu \mathrm{m}$.
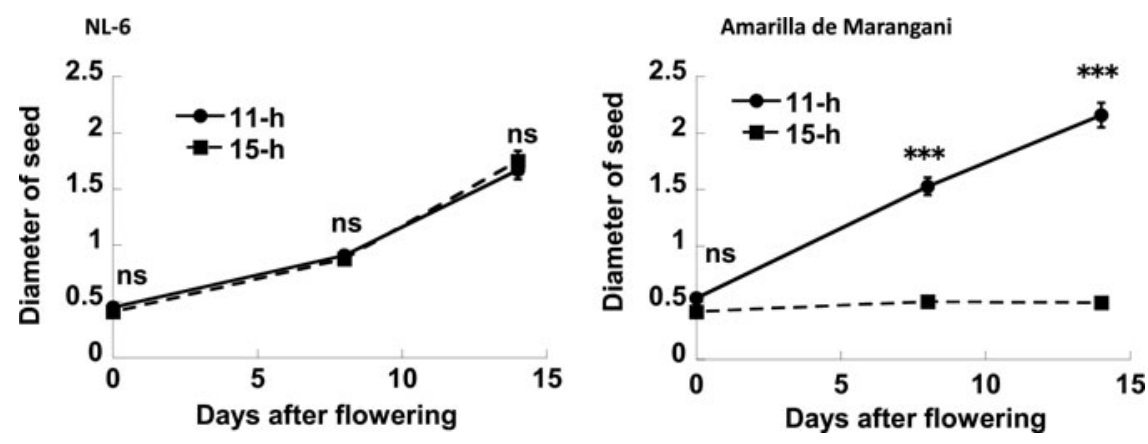

Figure 5. Effects of day length after flowering on the diameter of seed. ns, no significant difference; ${ }^{\star \star \star} 0.1 \%$ level of significant difference between 11 and $15 \mathrm{~h}$ by $t$-test, respectively. Replications $=3$.
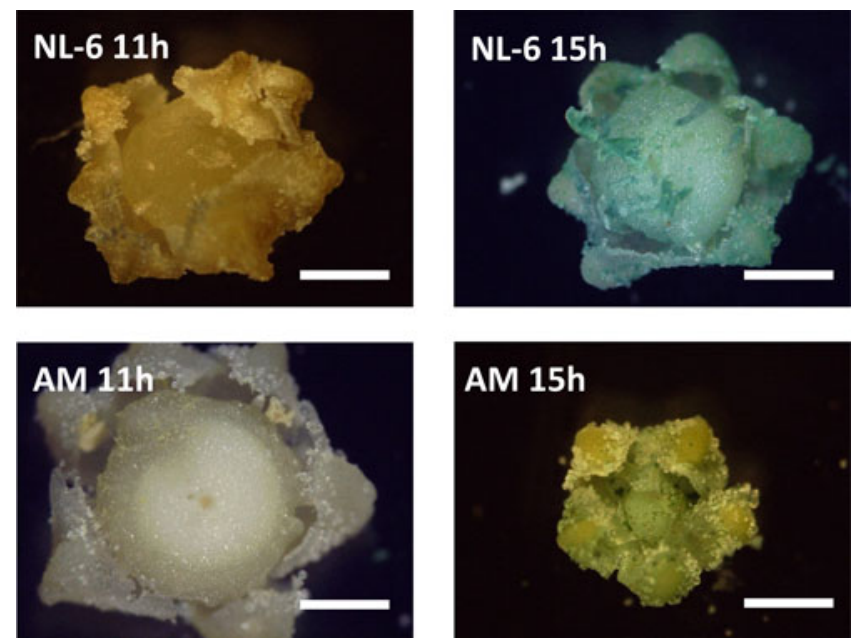

Figure 6. Seed growth at 14 days after flowering. Scale bar, $1 \mathrm{~mm}$.

experiment. Thus, to find out whether these varieties are representative of sea-level type and valley type quinoa, we should carry out similar experiments with many sea-level and valley type varieties in the future. Moreover, we observed only the elongation of pollen tube and early embryo formation under a $15 \mathrm{~h}$ day length regime. Evidently, these results do not guarantee success of fertilization. To prove success of fertilization, the determination of the ploidy of the embryo is necessary in future experiments.

Many studies have reported a change in the concentration of plant hormones or carbohydrates according to day length after the reproductive stage (Dorais et al., 1996; Nan et al., 2002;
Gibson, 2004). For example, Dorais et al. (1996) studied changes in photosynthetic efficiency and carbon partitioning under extended photoperiods (from 8 to $24 \mathrm{~h}$ ) in tomato (Lycopersicon esculentum Mill.) and sweet pepper (Capsicum annuum L.). Extending the photoperiod by means of supplemental lighting resulted in an increase in total carbohydrates $\left(\mathrm{CH}_{2} \mathrm{O}\right)$ produced in both species. In tomato, extended photoperiod principally affects shoot development. In contrast, an extended photoperiod did not increase shoot dry weight of sweet pepper plants. Nan et al. (2002) reported that wheat (Triticum aestivum L.) plants grown in continuous light had higher leaf ABA levels than plants grown using in an 18 or $21 \mathrm{~h}$ photoperiod. In quinoa, Bendevis et al. (2014) cultivated two differently adapted cultivars (Achachino and Titicaca) under long day length $(17.5 \mathrm{~h})$ and short day length $(10.0 \mathrm{~h})$ after the reproductive stages to clarify the effects of day length on the concentration of ABA and soluble sugars. This study suggested that both $\mathrm{ABA}$ and soluble sugars were regulators of the photoperiodic response leading to pronounced differences in reproductive developmental patterns between cultivars. The application of Paclobutrazol (GA-synthesis inhibitor), lead to an increase in seed number, from 308,000 to 432,000 seeds per $\mathrm{m}^{2}$ and in seed yield, from 517 to $791 \mathrm{~g}$ per $\mathrm{m}^{2}$, in the quinoa cultivar 2-Want (Gomez et al., 2011). Therefore, we would hypothesize that plant hormones or carbohydrate balance might affect embryo and seed growth in Amarilla de Marangani under specific day length regimes.

\section{Conclusions}

Pollen tube elongation and the formation of an early embryo in Amarilla de Marangani and NL-6 were not inhibited under the 
Table 1. Effects of day length after flowering on flower and seed number

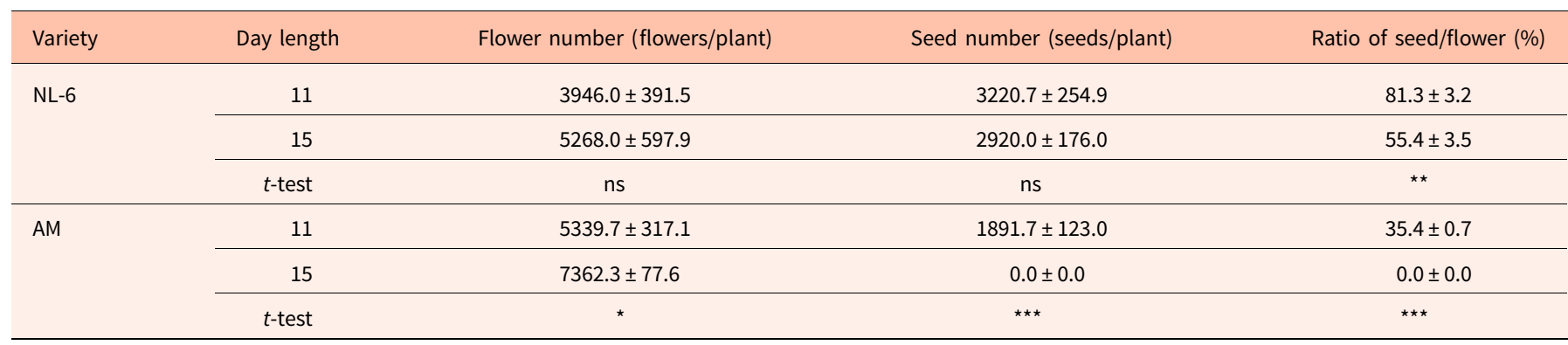

AM, Amarilla de Marangani; ns, no significant difference; ${ }^{\star \star \star} 0.1 \%,{ }^{\star \star} 1 \%$ and ${ }^{\star} 5 \%$ level of significant difference between 11 and $15 \mathrm{~h}$ by $t$-test, respectively; values are means \pm standard error; replications $=10$.

$11 \mathrm{~h}$ and the $15 \mathrm{~h}$ day length conditions after flowering. Embryo development after flowering in NL-6 was not inhibited under the $15 \mathrm{~h}$ day length condition. However, in Amarilla de Marangani, embryo development was inhibited under the $15 \mathrm{~h}$ day length condition. Thus, the cause of the decrease in seed number under the $15 \mathrm{~h}$ day length condition was the suspension of embryo development after fertilization.

\section{References}

Armeja I., Tanwar B. and Chauhan A. (2015) Nutritional composition and health benefits of golden grain of 21st century, Quinoa (Chenopodium quinoa Willd.): a review. Pakistan Journal of Nutrition 14, 1034-1040.

Bendevis M.A., Sun Y., Shabala S., Rosenqvist E., Liu F. and Jacobsen S.-E. (2014) Differentiation of photoperiod-induced ABA soluble sugar responses of two quinoa (Chenopodium quinoa Willd.) Journal of Plant Growth Regulation 33, 562-570.

Bertero H.D., King R.W. and Hall A.J. (1999) Photoperiod-sensitive development phases in quinoa (Chenopodium quinoa Willd.). Field Crops Research 60, 231-243.

Cheristiansen J.L., Jacobsen S.-E. and Jørgensen S.T. (2010) Photoperiodic effect on flowering and seed development in quinoa (Chenopodium quinoa Willd.). Acta Agriculturae Scandinavia Section B- Soil and Plant Science 60, 539-544.

Costa Tártara S.M., Manifesto M.M., Bramardi S.J. and Bertero H.D. (2012) Genetic structure in cultivated quinoa (Chenopodium quinoa Willd.), a reflection of landscape structure in Northwest Argentina. Conservation Genetics 13, 1027-1038.

Cure J.D., Patterson R.P., Raper Jr C.D. and Jackson W.A. (1982) Assimilate distribution in soybean as affected by photoperiod during seed development. Crop Science 22, 1245-1250.

Dorais M., Yelle S. and Gosselin A. (1996) Influence of extended photoperiod on photosynthates partitioning and export in tomato and pepper plants. New Zealand Journal of Crop Horticulture 24, 29-37.

Fuentes F.F., Martinez E.A., Hinrichsen P.V., Jellen E.N. and Maughan P.J. (2009) Assessment of genetic diversity patterns in Chilean quinoa (Chenopodium quinoa Willd.) germplasm using multiplex fluorescent microsatellite markers. Conservation Genetics 10, 369-377.

Galwey N.W. (1989) Quinoa. Biologist 36, 267-274.

Gibson S.I. (2004) Sugar and phytohormone response pathways: navigating a signaling network. Journal of Experimental Biology 55, 253-264.

Gomez M.B., Castro P.A., Mignone C. and Bertero H.D. (2011) Can yield potential be increased by manipulation of reproductive partitioning in quinoa (Chenopodium quinoa)? Evidence from gibberellic acid synthesis inhibition using Paclobutrazol. Functional Plant Biology 38, $420-430$.
Hirich A., Choukr-Allah R. and Jacobsen S.-E. (2014) Quinoa in Morocco. Effect of sowing dates on development and yield. Journal of Agronomy and Crop Science 200, 371-377.

Isobe K., Ujiie K., Hitomi S., Furuya Y. and Ishii R. (2012) Agronomic studies on quinoa (Chenopodium quinoa Willd.) cultivation in Japan - effects of day and night temperature after flowering time on seed thickening. Japanese Journal of Crop Science, 81, 167-172.

Isobe K., Sugiyama H., Okuda D., Murase Y., Harada H., Miyamoto M., Koide S., Higo M. and Torigoe Y. (2016) Effects of sowing time on the seed yield of quinoa (Chenopodium quinoa Willd) in South Kanoto, Japan. Agricultual Sciences 7, 146-153.

Lagercrantz U. (2009) At the end of the day: a common molecular mechanism for photoperiod responses in plants? Journal of Experimental Botany 60, 2501-2515.

Linnemann A.R. (1993) Phenological development in bambara groundnut (Vigna subterranean) at constant exposure to photoperiods of 10 to $16 \mathrm{~h}$. Annals of Botany 71, 445-452.

Lobell G., Fambrini M., Baraldi R., Lercari B. and Pugliesi C. (2000) Hormonal influence on photocontrol of the protandry in the genus Helianthus. Journal of Experimental Botany 51, 1403-1412.

Nan R., Carman J.G. and Salisbury F.B. (2002) Water stress, $\mathrm{CO}_{2}$ and photoperiod influence hormone levels in wheat. Journal of Plant Physiology 159, 307-312.

Repo-Carrasco R., Espinoza C. and Jacobsen S.-E. (2003) Nutritional value and use of the Andean crops quinoa (Chenopodium quinoa) and kañiwa (Chenopodium pallidicaule). Food Reviews International 19, 179-189.

Risi J. and Galwey N.W. (1984) The Chenopodium grains of the Andes: Inca crops for modern agriculture. Advanced in Applied Biology 10, $145-216$.

Risi J. and Galwey N.W. (1989) The pattern of genetic diversity in the Andean grain crop quinoa (Chenopodium quinoa Willd.). Multivariate methods. Euphytica 41, 135-145.

Risi J. and Galwey N.W. (1991) Effects of sowing date and sowing rate on plant development and grain yield of quinoa (Chenopodium quinoa) in a temperate environment. Journal of Agricultural Science, Cambridge 117, 325-332.

Summerfield R.J., Roberts E.H., Ellis R.H. and Lawn R.J. (1991) Towards the reliable prediction of time to flowering in six annual crops. The development of simple models for fluctuating field environments. Experimental Agriculture 27, 11-31.

Thomas J.F. and Raper Jr C.D. (1976) Photoperiodic control of seed filling for soybeans. Crop Science 16, 667-672.

Ujiie K., Sasagawa R., Yamashita A., Isobe K. and Ishii R. (2007) Agronomic studies on quinoa (Chenopodium quinoa Willd.) cultivation in Japan. Determination of the proper seeding time in the southern Kanto district for good performance of the grain yield. Japanese Journal of Crop Science 76, 59-64.

Wilson H.D. (1990) Quinua and relatives (Chenopodium sect. Chenopodium subsect. Cellulata). Economic Botany 44 (suppl), 92-110. 